\title{
Application of Anuga as a 2D surface irrigation model
}

\author{
$\underline{\text { M. Morris }}^{\text {a }}$, F. Githui a and A. Hussain a \\ a Agriculture Research and Development, \\ Department of Economic Development, Jobs, Transport and Resources, Victoria \\ Email:mike.morris@ecodev.vic.gov.au
}

\begin{abstract}
The dairy industry in the southern Murray Darling Basin (sMDB) is a major consumer of irrigation water, with over $90 \%$ of water applied to pastures and crops using border irrigation. While substantial investments have been made to improve regional and farm irrigation supply systems within the sMDB in the last decade, there has been little attention paid to improving the efficiency of conventional border irrigation design within fields. Border-check irrigation bays are typically rectangular, 40 to $80 \mathrm{~m}$ wide, 200 to $800 \mathrm{~m}$ long, and with surface elevation gradients of between 1 in 200 and 1 in 1000 . Conventional border irrigation designs are based on smoothly graded bay surfaces. These facilitate uniform application of water but are very inefficient with respect to surface drainage, with adverse consequences for irrigation efficiency, plant growth and water losses to deep drainage.
\end{abstract}

Investigation of alternatives to conventional border irrigation bay designs has been constrained by the lack of alternatives to conventional 1D surface irrigation models, which are of little use for simulation of water flow on non-uniform surfaces. The application of 2D models in studies of surface irrigation has to date been limited. For our purpose a model was required that adequately represented the processes of both flooding and draining of uneven surfaces with low elevation gradients. To address this we have applied the 2D hydrodynamic surface water flow model, Anuga, and tested it against field data acquired from irrigations both before and after modification of a field surface.

Our irrigation bay was $39.1 \mathrm{~m}$ wide and $253.1 \mathrm{~m}$ long with a mean elevation gradient of 1 in 650 . The bay modification was installation of four shallow surface drains evenly spaced across the bay and extending from $10 \mathrm{~m}$ from the top to the end of the bay. Anuga simulations of three irrigations on the unmodified bay surface corresponded closely with measured data and output from SISCO, an established 1D surface water flow model. After modification of the field surface, simulations of a further three irrigations with Anuga corresponded well with measured data, capturing the reduction in surface drainage duration in measured data. A simplified representation of the surface drains installed on the bay also provided satisfactory simulations of irrigation events on the modified bay while substantially reducing model run times.

Successful application of Anuga for simulation of border irrigation provides an exciting opportunity for development of more efficient border irrigation bay designs. Candidate designs for future field evaluation are now being explored.

Keywords: Anuga, 2D surface irrigation model, border irrigation 


\section{INTRODUCTION}

The dairy industry is a major water user in the southern Murray Darling Basin (sMDB), irrigating pastures and fodder crops to produce approximately 2.3 billion litres of milk in 2013/14. In the past decade the creation of water markets, reduced water allocations and substantial investments in 'modernised' water infrastructure have driven substantial improvements in water management and irrigation efficiencies on farms in the region. Water can now be delivered to farms with greater precision and with shorter lag between the times of ordering and delivery. Use of irrigation automation on farms is reducing operating costs and improving efficiencies.

Border irrigation is by far the most common irrigation system used by the dairy industry in the sMDB. Fields are divided by low check banks into smoothly graded, rectangular bays that, depending on the soil type and terrain, are typically 40 to $80 \mathrm{~m}$ wide, 200 to $800 \mathrm{~m}$ long, and with gradients of between 1 in 200 and 1 in 1000 . Sufficient water is applied from a farm channel outlet at the top of each bay to water the entire bay. A surface drain at the foot of bays directs runoff to a re-use sump. Advantages of border irrigation include its relatively low capital cost and minimal ongoing energy costs because gravity drives all water distribution.

Graded bay surfaces rapidly develop uneven microtopography, which with slow final infiltration rates cause the duration of surface ponding within irrigation bays to vary by more than 24 hours. Under these conditions the feasible degree of precision in irrigation scheduling and water application is limited. Uncontrolled surface ponding increases potential deep drainage losses and consequent environmental impacts, and adversely affects productivity in pastures subjected to irrigation wetting and drying cycles (Donohue et al., 1984; Dunbabbin et al., 1997).

This paper describes application of the Anuga 2D surface water flow model for simulation of surface irrigation model in order to explore the effectiveness of alternative bay surface designs in reducing the duration and variability of surface water ponding. The key requirement of the model for our application is an ability to accurately rank different irrigation bay surface designs with respect to the duration of surface water ponding.

Anuga solves the shallow water wave equations using a finite volume method propagated across a model domain which is a topographic surface represented by an irregular triangular mesh (Nielsen et al., 2005). A mesh may contain holes, breaklines and internal regions having distinct attributes. Functions exist for initial assignment of values for vertex attributes such as surface elevation, hydraulic roughness and the initial conditions of water depth and momentum. Edges of the model domain are identified during mesh creation and can be linked to either predefined or custom functions that control the behaviour of each domain boundary. Processes such as inflow and infiltration can be applied to the centroids of mesh triangles using Anuga "operator" functions. The model runs by calculating the values of the dependent variables of water depth and two-dimensional horizontal momentum over time at each mesh cell vertex. Quantities such as surface water stage and momentum are output to a NetCDF file at intervals and for a duration that are userdefined. Anuga is open source software developed in the Python programming language, with computationally intensive routines implemented in $\mathrm{C}$, and is available at https://anuga.anu.edu.au/. Importantly for our application, Anuga can simulate the wetting and drying of mesh cells as surface water advances and recedes.

\section{METHODS}

\subsection{The Anuga model}

In our implementation the model domain was a single border irrigation bay (Figure 1). The top of the bay and the left and right checkbanks were represented as reflective boundaries, while free drainage at the foot of the bay was represented by a Dirichlet boundary having constant zero momentum and a constant surface water elevation less than the bay surface. The bay surface mesh vertices were assigned elevation, which may be topographic survey data or generated alternative bay surfaces. Irrigations were implemented with an inlet operator which applied an inflow hydrograph at the top of the bay. 


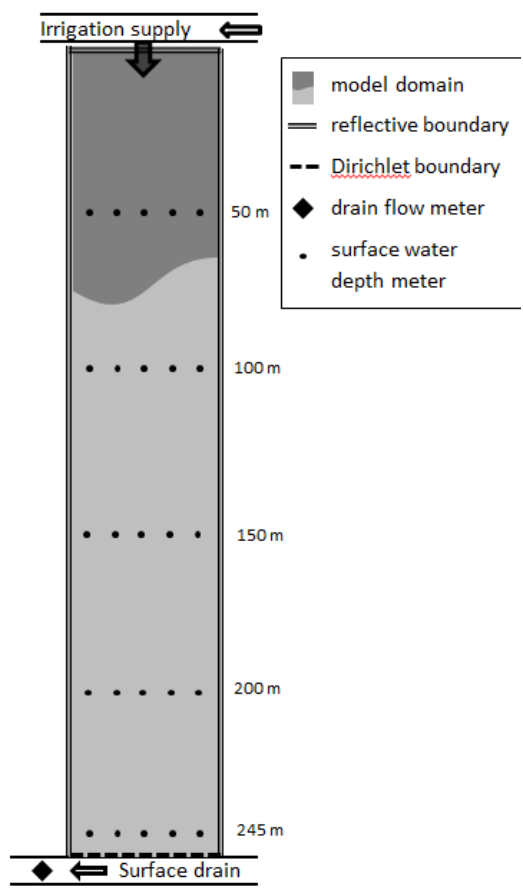

Figure 1. Diagram of the model domain and field measurement locations.

\subsection{The site}

Model test data were obtained from a 253.1 x $39.1 \mathrm{~m}$ irrigation bay with an average surface elevation gradient of 1 in 650 . The bay had a perennial ryegrass pasture which was grazed once during the data acquisition period. The soil profile featured a loam topsoil with an abrupt texture change at approximately 200 $\mathrm{mm}$ depth to a relatively impermeable clay subsoil which cracked when dry.

We measured three irrigations prior to the farmer modifying the bay surface with four shallow surface drains installed with a rotary drain digger. The four surface drains were approximately evenly spaced across the irrigation bay, starting about $10 \mathrm{~m}$ from the top and extending to the farm drain at the end of the field. Depth of the drains varied irregularly down their length from 10 to $30 \mathrm{~mm}$. Following installation of the surface drains we used a robotic total station to acquire approximately 2,000 precision survey elevations on the bay. A further three irrigations on the modified bay surface were then measured.

Data acquired for each irrigation included the bay inflow measured by magnetic flow meter, surface water depth hydrographs measured with 25 capacitance water depth meters placed at 5 evenly spaced points across the bay at 50,100, 150, 200 and $245 \mathrm{~m}$ from the top of the bay. Runoff was measured with an acoustic doppler flow meter in the field drain, and for irrigation 6 , with flumes at the end of each bay surface drain.

\subsection{Calibration of infiltration and roughness parameters}

Infiltration should account for most inflow during an irrigation event and should therefore be the second largest flux, so to be useful as a surface irrigation model, Anuga had to simulate infiltration. An infiltration operator, based on the modified Kostiakov (MK) equation (Equation 1), was developed.

$Z=k t^{a}+f_{0} t+C$

Here cumulative infiltration $Z$ is a function of the duration of inundation $t$, the empirical parameters $a, k$ and $f_{0}$, and a time independent term, $C$, that that accounts for rapid initial infiltration due to macropores and adsorption. Values for the MK equation parameters and for the Manning roughness coefficient were determined for irrigations 1,2 and 3 by fitting the 1D SISCO surface irrigation model to our field measurement data. The SISCO model applies the one-dimensional form of the full hydrodynamic SaintVernant equations for continuity and momentum, and provides a calibration module for determining values for the MK parameters and Manning roughness coefficient (Gillies and Smith, 2015).

Irrigations 4, 5 and 6 occurred after bay surface modification and therefore could not be adequately simulated with a $1 \mathrm{D}$ model. An alternative approach was therefore required for calibration of the infiltration parameters for these events. Robertson et al. (2004) investigated approaches for determining infiltration parameter values from field observations for the Analytical Irrigation Model (AIM) surface irrigation model (Austin and Prendergast, 1997). The AIM model has a linear cumulative infiltration function (i.e. Equation 1 with $k=0$ ), which has been shown to be well suited to the majority of irrigated soil types in the sMDB (Austin and Prendergast, 1997).

On a site with the same soil type as our site, Robertson et al. (2004) found that $C$

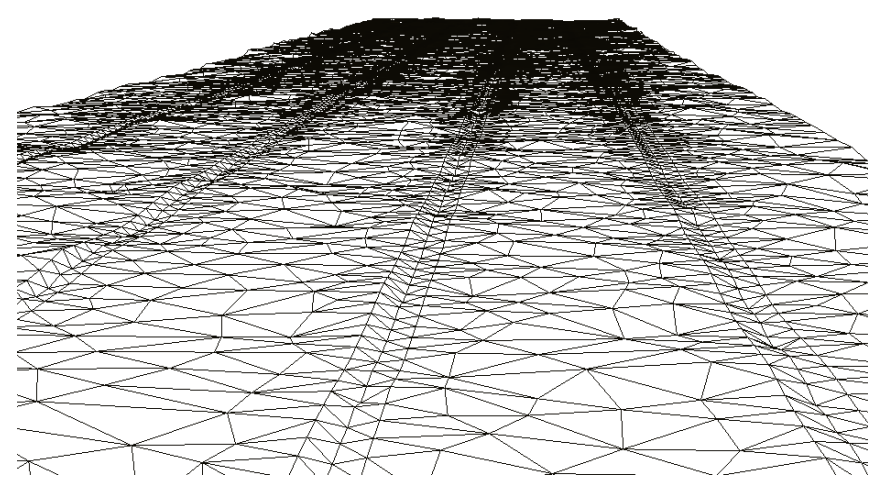

Figure 2. Triangular mesh of an irrigation bay with surface drains incised into it. The vertical is exaggerated by a factor of 10 . 
was $75 \%$ of irrigation deficit over a wide range of deficits, and also concluded that $f_{0}$ could be regarded as a property of the soil profile that would not normally vary between irrigations. Accordingly, we estimated $C$ for irrigations 4, 5 and 6 as $75 \%$ of estimated irrigation deficit calculated by the method of Allen et al. (1998) prior to each of these irrigations. We determined $f_{0}$ to be $0.96 \mathrm{~mm} / \mathrm{h}$, which was the average final infiltration rate of irrigations 1, 2 and 3, based on the slope of the linear regression of calibrated cumulative infiltration after one hour. To test this approach, we also applied this methodology back onto irrigations 1, 2 and 3.

The dairy herd grazed the field in the period between irrigations 2 and 3 did not cause a substantial change the SISCO calibrated value of $n$ for these irrigations. There were no apparent changes to the irrigation bay surface throughout the measurement period other than the surface drains installed between irrigations 3 and 4. We therefore used the average of optimised Manning coefficients from irrigations 1, 2 and 3 as the value of $n$ for the field surface in irrigations 4,5 and 6.

\subsection{Representation of surface drains}

The shallow surface drains installed after irrigation 3 presented challenges for simulation. The width of each drain in the field did not exceed about $30 \mathrm{~cm}$, which if represented accurately in the model, would have led to very large meshes. Our initial approach was to approximate the drains by incising into the digital bay surface a drain with a simple $\mathrm{V}$ cross section (Figure 2). Elevation of the base of each drain in the simulation varied down its length with variations in proximal surface elevation, reflecting the form of the drains installed in the field. Drain depth was set to $0.01 \mathrm{~m}$ to create a flow rate, calculated with Manning's equation, that was similar to the actual drain cross section. The drain Manning friction coefficient was assumed to be 0.02 (Esfandiari and Maheshwari, 1998).

Representation of surface drains in this way created much more complex triangular meshes. Our objective in using Anuga is to search for improved irrigation bay designs, which we anticipate will require many model runs. Given that simplification of the triangular mesh is an effective way to reduce the model run time, we have explored more simplified mesh representations of surface drains, including implementing the drains with zero depth, with only surface roughness providing a preferential flow pathway.

\subsection{Model performance}

Model performance was assessed by comparing the average of observed and simulated depth hydrographs at five evenly spaced locations at 50,100, 150, 200 and $245 \mathrm{~m}$ from the top of the irrigation bay. Average hydrographs were compared using the Nash-Sutcliffe coefficient of efficiency (NSE), percentage bias (PBIAS) and root mean square error - observation standard deviation ratio (RSR) (Moriasi et al., 2007).

\section{RESULTS}

\subsection{Comparisons with measurement data}

Information on each irrigation is provided in Table 1.

Table 1. Summary of measured irrigations.

\begin{tabular}{cccccccc}
\hline \multirow{2}{*}{ Irrigation } & Date & $\begin{array}{c}\text { Duration } \\
(\mathrm{min})\end{array}$ & $\begin{array}{c}\text { Inflow } \\
\left(\mathrm{m}^{3}\right)\end{array}$ & $\begin{array}{c}\text { Runoff } \\
\left(\mathrm{m}^{3}\right)\end{array}$ & & $\begin{array}{c}\text { Simfiltration } \\
\left(\mathrm{m}^{3}\right)\end{array}$ & $\begin{array}{c}\text { Runoff } \\
\left(\mathrm{m}^{3}\right)\end{array}$ \\
\hline 1 & 3 Feb 2015 & 74 & 667 & 376 & & 348 & 315 \\
2 & 10 Feb 2015 & 73 & 588 & 198 & & 358 & 224 \\
3 & 17 Feb 2015 & 73 & 606 & 198 & & 318 & 285 \\
4 & 3 Mar 2015 & 73 & 623 & 257 & & 277 & 342 \\
5 & 10 Mar 2015 & 73 & 594 & 267 & & 264 & 327 \\
6 & 17 Mar 2015 & 60 & 416 & 154 & & 260 & 154 \\
\hline
\end{tabular}

Table 2 provides the infiltration parameter and Manning roughness coefficient values determined with the calibration module of the SISCO model. Performance coefficients indicate that Anuga was simulating depth hydrographs on the irrigation bay surface satisfactorily, with a consistent underestimation of depth.

Anuga simulations of irrigations 1,2 and 3 using infiltration parameters and Manning n values calibrated with SISCO agreed closely with 1D SISCO model output. Depth hydrographs at specific distances down the field differed between the models as a consequence of the irregular surface represented in Anuga, however runoff hydrographs corresponded closely, as for example in Figure 3. 
Table 2. Anuga model performance with infiltration and roughness coefficients calibrated with the SISCO model.

\begin{tabular}{|c|c|c|c|c|c|c|c|c|}
\hline \multirow[b]{2}{*}{ Irrigation } & \multicolumn{4}{|c|}{ Infiltration parameters } & \multirow[b]{2}{*}{$n$} & \multicolumn{3}{|c|}{ Model performance } \\
\hline & $a$ & $\begin{array}{c}k \\
\mathrm{~mm} / \mathrm{h}^{\mathrm{a}}\end{array}$ & $\begin{array}{c}f_{0} \\
\mathrm{~mm} / \mathrm{h}\end{array}$ & $\begin{array}{c}C \\
\mathrm{~mm}\end{array}$ & & NSE & $\begin{array}{c}\text { PBIAS } \\
\%\end{array}$ & RSR \\
\hline 1 & 0.1046 & 32.41 & 0 & 0 & 0.21 & 0.92 & -13.6 & 0.28 \\
\hline 2 & 0.0969 & 39.67 & 0 & 0 & 0.21 & 0.90 & -16.6 & 0.31 \\
\hline 3 & 0.1686 & 30.95 & 0 & 0 & 0.20 & 0.88 & -17.7 & 0.34 \\
\hline
\end{tabular}

mean square error - observation standard deviation ratio.

Table 3 provides Anuga performance coefficients for each of the six measured irrigations with $C$ calculated as $75 \%$ of the irrigation deficit and $f_{0}$ assumed constant and the average of the slopes of the linear regressions through the SISCO calibrated cumulative infiltrations of irrigations 1, 2 and 3. Comparing results for calibration with SISCO (Table 2) and with irrigation deficit, model performance coefficients are similar for irrigations 1, 2 and 3 using either calibration method. Nash-Sutcliffe and RSR coefficient values are satisfactory and the negative percentage bias is consistent across both calibration methods.

Table 3. Anuga model performance with infiltration coefficient $C=75 \%$ of irrigation deficit, $f_{0}=$ the average of irrigation 1,2 and 3 infiltration rate after $1 \mathrm{~h}$, and $n=$ average $n$ of irrigations 1,2 and 3 .

\begin{tabular}{|c|c|c|c|c|c|c|c|c|}
\hline \multirow[b]{2}{*}{ Irrigation } & \multicolumn{4}{|c|}{ Infiltration parameters } & \multirow[b]{2}{*}{$n$} & \multicolumn{3}{|c|}{ Model performance } \\
\hline & $a$ & $\begin{array}{c}k \\
\mathrm{~mm} / \mathrm{h}^{\mathrm{a}}\end{array}$ & $\begin{array}{c}f_{0} \\
\mathrm{~mm} / \mathrm{h}\end{array}$ & $\begin{array}{c}C \\
\mathrm{~mm}\end{array}$ & & NSE & $\begin{array}{c}\text { PBIAS } \\
\%\end{array}$ & RSR \\
\hline 1 & 0 & 0 & 0.96 & 31.1 & 0.21 & 0.93 & -11.7 & 0.27 \\
\hline 2 & 0 & 0 & 0.96 & 32.3 & 0.21 & 0.84 & -5.3 & 0.40 \\
\hline 3 & 0 & 0 & 0.96 & 28.1 & 0.21 & 0.87 & -10.3 & 0.36 \\
\hline 4 & 0 & 0 & 0.96 & 24.7 & 0.21 & 0.83 & 10.0 & 0.41 \\
\hline 5 & 0 & 0 & 0.96 & 23.4 & 0.21 & 0.79 & 2.3 & 0.46 \\
\hline 6 & 0 & 0 & 0.96 & 23.3 & 0.21 & 0.85 & -0.5 & 0.39 \\
\hline
\end{tabular}

mean square error - observation standard deviation ratio.

On the basis of the very similar performance of the SISCO and irrigation deficit calibrations, the deficit calibrations were used for all irrigations in subsequent simulations.

Model performance coefficients for irrigations 4, 5 and 6 indicate that Anuga provides a reasonable representation of surface water flows on the modified bay.

Figure 3 provides example output of average depth hydrographs at discrete distances down the length of the

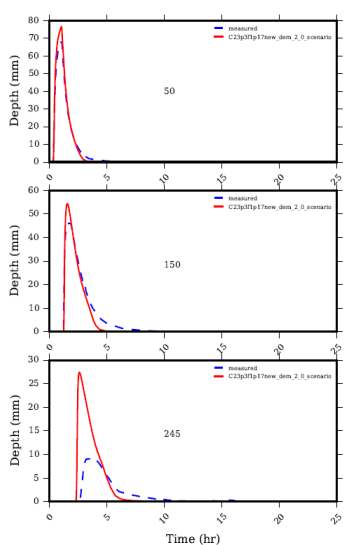

Figure 3. Measured and simulated average depth hydrographs for irrigation 6 at 50,100,150,200 and $245 \mathrm{~m}$ from the top of the field.

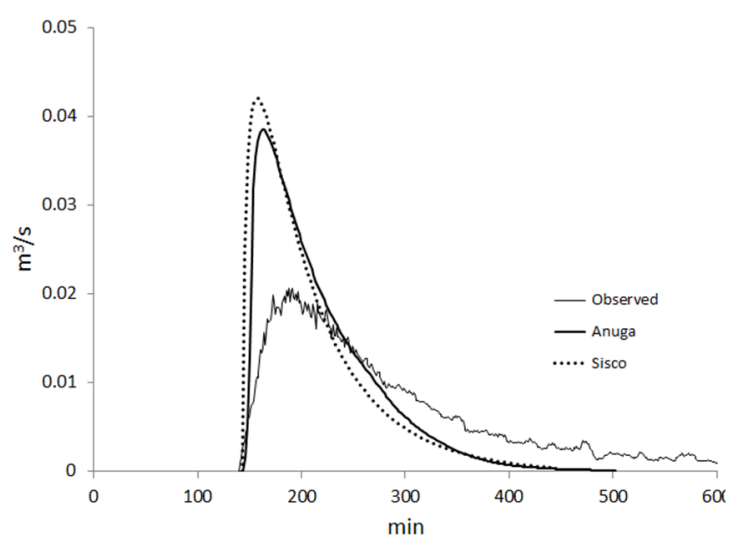

Figure 4. Measured and simulated runoff from Irrigation 1. 
irrigation bay. Simulated depth hydrographs accurately reflect measured data in the first $100 \mathrm{~m}$, but increasingly overestimate the depth hydrograph peak and underestimate the duration of surface water with greater distance down the field. Greater peak depth of surface water in the depth hydrographs on the bay led to early, overestimated peak runoff hydrographs, as in Figure 4.

Simulation of the surface water advance, or start of depth hydrographs, was close to measured data in all simulations, as was the start of the runoff hydrograph.

\subsection{Representation of surface drains}

More approximate representations of surface drains were tested with the aim of reducing model run times. Table 4 shows model performance for each irrigation with the four drains installed prior to irrigations 4,5 and 6 represented as $2 \mathrm{~m}$ wide regions having zero drain depth. With this specification, preferential flow in the drain was caused only by the lower drain surface roughness compared to the bay surface.

Model performance measures are similar to the simulations with drains simulated at $1 \mathrm{~m}$ width and $0.01 \mathrm{~m}$ depth, indicating that simplified representation is feasible for small surface features such as drains. The impact on model run times for irrigations having surface drains was substantial, with run times reduced by $90 \%$.

Table 4. Anuga performance coefficients with surface drains simulated $2 \mathrm{~m}$ wide and with zero depth.

\begin{tabular}{cccc}
\hline Irrigation & NSE & $\begin{array}{c}\text { PBIAS } \\
\%\end{array}$ & \multicolumn{1}{l}{ RSR } \\
\hline 4 & 0.67 & -9.0 & 0.58 \\
5 & 0.57 & -11.4 & 0.66 \\
6 & 0.63 & -15.9 & 0.61
\end{tabular}

NSE is the Nash-Sutcliffe coefficient of efficiency; PBIAS is the percent bias; RSR is the root mean square error observation standard deviation ratio.

\section{DISCUSSION}

The Anuga model has simulated irrigation events on unmodified irrigation bays and produced results equivalent to an established 1D surface irrigation model. Following modification of the bay surface with installation of four surface drains, Anuga satisfactorily simulated three irrigations on the modified bay surface.

As with any surface irrigation model, accuracy in the simulation of surface water flows, infiltration and runoff is dependent on the accuracy of inflow measurement and infiltration parameter estimates. Similar to established 1D surface irrigation models, surface drainage was not well simulated by Anuga late in each event, with ponding duration underestimated when surface water flow rate and water depth were low. Despite these issues, Anuga captured the effect of the surface drains on ponding duration well.

Bearing in mind that our requirement is for a model able to merely rank bay surface designs with respect to their surface water ponding duration, the Anuga model appears well suited. For example, Figure 5 shows the simulated area inundated for different durations of water ponding on the bay surface for irrigation 3 , prior to the installation of the surface drains, and for irrigation 6 , after drain installation. The effect on surface water ponding duration due to the surface drain treatment can be clearly distinguished in both the $1 \mathrm{~m}$ wide, $0.02 \mathrm{~m}$ deep and $2 \mathrm{~m}$ wide $0 \mathrm{~m}$ deep drain simulations.
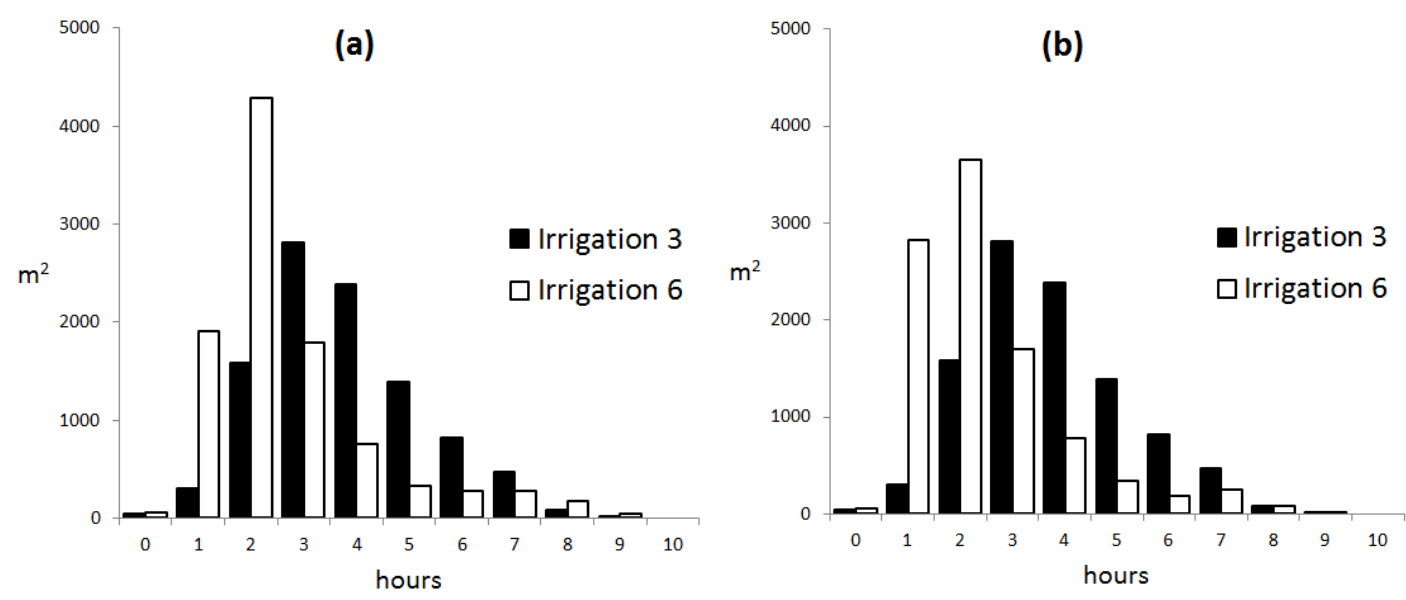

Figure 5. Simulated duration of surface ponding for irrigation 3, prior to installation of drains, and irrigation 6 , after installation of surface drains simulated with (a) $1 \mathrm{~m}$ wide, $0.01 \mathrm{~m}$ deep $\mathrm{V}$ cross sections and (b) $2 \mathrm{~m}$ wide zero depth cross sections. 


\section{CONCLUSIONS}

The Anuga 2D surface water flow model has been adapted for use as a surface irrigation model and evaluated against data acquired from irrigations measured both before and after the installation of shallow surface drains. The SISCO 1D surface irrigation model was used to provide calibrated values for infiltration parameters and the roughness coefficient for three irrigations measured prior to field modification. Using these values, Anuga performance was comparable with SISCO, with average Nash-Sutcliffe coefficient of efficiency (NSE), root mean square error (RSR) and percent bias values of $0.90,0.31$ and -16\% respectively.

An alternative calibration method was required for irrigations measured after installation of shallow drains on the bay surface. These calibrations resulted in average NSE, RSR and percent bias values of $0.82,0.42$ and $3.9 \%$ respectively for the three irrigations measured after installation of the surface drains on the bay.

We have shown that ANUGA, fitted with an appropriate infiltration function can simulate border check irrigations on relatively smooth bay surfaces and on bay surfaces that have been modified to improve surface drainage. This gives us confidence to use it in designing alternative bay designs that can improve irrigation performance.

\section{ACKNOWLEDGMENTS}

Thanks to Tony Cook for excellent technical assistance and to the dairy farmers who have hosted our work. This research has been supported by Dairy Australia and the Victorian Department of Economic Development, Jobs, Transport and Resources.

\section{REFERENCES}

Allen, R.G., Pereira, L.S., Raes, D., Smith, M. (1998). FAO Irrigation and Drainage Paper No. 56 Crop Evapotranspiration (guidelines for computing crop water requirements).

Austin, N.R., Prendergast, J.B. (1997). Use of kinematic wave theory to model irrigation on cracking soil. Irrigation Science 18, 1-10.

Donohue, G.I., Greene, R.S.B., Willoughby, P., Wilson, I.B. (1984). The effect of waterlogging on flood irrigated perennial ryegrass, in: Root Zone Limitations to Crop Production on Clay Soils. Presented at the Symposium of the Australian Society of Soil Science Inc Riverina Branch, CSIRO, Australia, Griffith, NSW, pp. 85-92.

Dunbabin, J.S., Hume, I.H., Ireson, M.E. (1997). Effects of irrigation frequency and transient waterlogging on the production of a perennial ryegrass-white clover pasture. Australian Journal of Experimental Agriculture 37, 165-171.

Esfandiari, M., Maheshwari, B. (1998). Suitability of Selected Flow Equations and Variation of Manning's n in Furrow Irrigation. J. Irrig. Drain Eng. 124, 89-95.

Gillies, M.H., Smith, R.J. (2015). SISCO: surface irrigation simulation, calibration and optimisation. Irrig Sci $1-17$.

Moriasi, D.N., Arnold, J.G., Van Liew, M.W., Bingner, R.L., Harmel, R.D., Veith, T.L. (2007). Model Evaluation Guidelines for Systematic Quantification of Accuracy in Watershed Simulations. Transactions of the ASABE 50, 885-900.

Nielsen, O., Roberts, S., Gray, D., McPherson, A., Hitchman, A. (2005). Hydrodynamic modelling of coastal inundation, in: Zerger, A. and Argent, R.M. (eds) MODSIM 2005 International Congress on Modelling and Simulation. Modelling and Simulation Society of Australia and New Zealand, pp. 518-523.

Robertson, D., Wood, M., Wang, Q.J. (2004). Estimating hydraulic parameters for a surface irrigation model from field conditions. Australian Journal of Experimental Agriculture 44, 173-179. 